\title{
Unidirectional Cordenka Fibre-Reinforced Furan Resin Full Biocomposite: Properties and Influence of High Fibre Mass Fraction
}

\author{
Talent Malaba and Jiajun Wang \\ College of Materials and Textiles, Zhejiang Sci-Tech University, Hangzhou 310018, China \\ Correspondence should be addressed to Jiajun Wang; wangjjhz@163.com
}

Received 23 June 2015; Revised 14 August 2015; Accepted 30 August 2015

Academic Editor: Laurent Orgéas

Copyright (C) 2015 T. Malaba and J. Wang. This is an open access article distributed under the Creative Commons Attribution License, which permits unrestricted use, distribution, and reproduction in any medium, provided the original work is properly cited.

\begin{abstract}
A full biocomposite was fabricated from Cordenka CR fibre and furan resin. High fibre mass fractions (FMF) were achieved by pressing the CR fibres into unidirectional sheets prior to incorporation into the resin. Results of testing indicated that the tensile properties of the biocomposite were improved by the initial increase of FMF from 51 to 64\%, with a subsequent increase of FMF to $75 \%$ resulting in a deterioration of those properties. Examination of the tensile fracture surfaces with a scanning electron microscope (SEM) revealed moderate deterioration in fibre-matrix adhesion after the initial increase of FMF. Further increase of the FMF to $75 \%$ was shown by SEM to result in worse fibre-matrix adhesion. On the other hand, the flexural, interlaminar-shear, and dynamic mechanical properties were adversely affected by the increase in fibre-mass fraction from 51 through $75 \%$. These effects were mainly attributed to reduced fibre wetting that resulted in weakened fibre-matrix interfacial bonding and subsequent poor stress exchange at the fibre-matrix interface. Observations made with a digital microscope revealed normal crack behaviour in the laminated composite, and the shear fracture modes were I and II. This biocomposite has mechanical properties comparable to those of flax and glass fibre-reinforced furan resin biocomposites.
\end{abstract}

\section{Introduction}

Biocomposites are composite materials that consist of either a bio-derived matrix or biofibre reinforcement or both. Companies and research institutions are developing biocomposites mainly because of heightening environmental conscience amongst the public, government legislation, the depletion of raw materials for synthetic polymers, and price increases [1].

A bio-derived matrix is known as a bioresin [2]. One type of thermosetting bioresin is called furan resin. At room temperature, furan resin is a reddish-brown liquid consisting of prepolymers of furfuryl alcohol (2-furanmethanol), which can cross-link into a solid thermoset polymer called polyfurfuryl alcohol (PFA). This cross-linking is accelerated by heat and acid catalysts [3]. To produce furfuryl alcohol, plantsourced hemicellulose is hydrolysed in acidic conditions into pentose sugars [4]. The five-carbon sugars are then hydrolysed under the same conditions into the aldehyde furfural (furan-2-carbaldehyde), which is then reduced into furfuryl alcohol [5]. Furan resins are used in the manufacture of corrosion resistant fibre-reinforced plastics (FRPs) because the polymer has excellent chemical resistance and is particularly good at handling solvents and aggressive service environments [6]. Some FRP manufacturers also select furan resins due to their high temperature performance, which has been found to exceed $200^{\circ} \mathrm{C}$ in some furan based laminates [6].

The adoption of long unidirectional natural fibres as reinforcement in bioresins can result in "full biocomposites" with enhanced mechanical properties and the potential for use in more structural applications [7]. Natural fibres, however, tend to possess poorer mechanical properties when compared to their synthetic counterparts. They are also prone to large variations in measurable parameters, such as length, diameter, and strength, even within the same batch [2]. 
These naturally occurring variations are almost inevitable and can make the design and quality control of natural fibrereinforced biocomposites challenging.

To continue relying on biomass as raw material, rayon fibre is a viable option to overcome some challenges posed by natural fibres [8]. Rayon fibre is made from purified cellulose sourced from plant material, particularly wood pulp. A variant of the manufacturing process yields high tenacity rayon (HTR) which, as its name suggests, exhibits high tensile strength. Cordenka GmbH \& Co. KG (Obernburg, Germany) make a type of HTR called CR fibre for composite applications [9]. The CR fibre has tensile strength of $850 \mathrm{MPa}$, an elastic modulus of $19.5 \mathrm{GPa}$, and an elongation at break of $12 \%$ $[9,10]$. Due to these properties, thermoplastics reinforced with this fibre possess a significant energy absorption capacity, which translates to a high degree of impact resistance [10]. The research into the application of CR fibres in thermoset based composites is still ongoing [10].

In most previous studies of furan based natural fibrereinforced composites, the proportion of the fibre reinforcement has been below $50 \%[7,11,12]$. However, it has been suggested that to attain high mechanical strength levels (>200 MPa), the fibre proportion must exceed 50\% [12]. One proposed technique for achieving a high fibre proportion in these laminates is to compact the natural fibres into unidirectional sheets before their incorporation into the resin [12]. Thus, in the current study, a full biocomposite has been fabricated through wet lay-up and compression moulding using CR fibre sheets and furan resin. Composite specimens with high fibre proportions are obtained and tested to evaluate the properties of the composite, as well as the influence of the high fibre proportion on the tensile, flexural, and interlaminar shear strengths of the composites. Digital microscope and scanning electron microscope (SEM) are employed to analyse the fractured specimens. In addition, the viscoelastic behaviour of the composite is studied using dynamic mechanical analysis (DMA), whilst thermogravimetric analysis (TGA) is conducted for an evaluation of the thermostability of the biocomposite. The results of these tests will also serve to assess the feasibility of applying the CR fibre-reinforced furan resin full biocomposite in the relevant industries.

\section{Materials and Methods}

2.1. Materials. High tenacity rayon of the type (Cordenka) CR fibre with a linear density of 1840 dtex and zero twist was obtained in wound package form from Cordenka $\mathrm{GmbH}$ \& Co. KG (Obernburg, Germany). Furan resin was sourced from Hangzhou Tianyu Chemicals Co. Ltd. (Xiaoshan, Hangzhou, China). The resin had the molecular formula $\left(\mathrm{C}_{5} \mathrm{H}_{6} \mathrm{O}_{2}\right)_{n}$, where $n \geq 2$; the purity was $80 \%$ with about $20 \%$ moisture, $30 \mathrm{mPa} \cdot \mathrm{s}$ viscosity $\left(20^{\circ} \mathrm{C}\right), 1.16 \mathrm{~g} / \mathrm{cm}^{3}$ density, and a $\mathrm{pH}$ of 7 . The resin manufacturer also provided the resin's curing agent: p-toluenesulphonic acid (4methylbenzenesulphonic acid).

2.2. Fibre Preparation. The CR fibres were unwound from the package, cut, and evenly laid into 36 individual sheets with dimensions of $280 \times 70 \mathrm{~mm}^{2}$; each sheet had a mass of approximately $10 \mathrm{~g}$. The sheets were separately wrapped in aluminium foil and compacted in a hot press at $10 \mathrm{MPa}$ and $80^{\circ} \mathrm{C}$ for 2 hours to form flat and firm sheets consisting of unidirectional fibres. The compacted fibre sheets were finally arranged into three discrete sets, where in the first set the sheets were layered into double plies, triple plies in the second set, and quadruple plies in the third set. Each set had four stacks of the sheets, with the mass of a stack in set 1 being $20 \mathrm{~g}, 30 \mathrm{~g}$ in set 2 , and $40 \mathrm{~g}$ in set 3 .

2.3. Resin Preparation. $350 \mathrm{~mL}$ of the furan resin was poured into a $500 \mathrm{~mL}$ glass beaker and stirred without heating using a magnetic stirrer. The curing agent was then gradually added into the beaker in five $3 \mathrm{~g}$ partitions to avoid the potentially violent cross-linking reaction. The mixture was continuously stirred for approximately 20 minutes, or until its temperature reached $45^{\circ} \mathrm{C}$, as indicated by a mercury thermometer.

2.4. Composite Laminates Fabrication. The composite laminates were prepared inside a $2 \mathrm{~mm}$ thick aluminium mould with dimensions $300 \times 300 \times 20 \mathrm{~mm}^{3}$. The mould had first been sprayed with mould release agent (Daifree GA 7550, Daikin Fluorochemicals China Co. Ltd.). The four fibre stacks from set 1 were laid side by side inside the mould. The hot resin/curing agent mixture was then poured into the mould to thoroughly wet the fibres. The moulding of furan resin is done in two steps: drying and then curing. Thus, prior to curing, the wet laminates were placed inside a vacuum oven at $45^{\circ} \mathrm{C}$ for 1 hour to remove the moisture from the resin [7]. The aluminium mould was then placed inside a compression moulding machine to cure the laminates.

2.5. Curing the Laminates. Curing was done at $10 \mathrm{MPa}$ pressure using an adapted multistep sequence [13]. The temperature was kept at $40^{\circ} \mathrm{C}$ for 12 hours, then raised to $60^{\circ} \mathrm{C}$ to remain there for another 12 hours, and then increased to $80^{\circ} \mathrm{C}$ and kept there for 6 hours. The temperature was finally increased to $110^{\circ} \mathrm{C}$ and the pressure released to $0 \mathrm{MPa}$ to postcure the laminates for 1 hour. The temperature was increased gradually in order to slowdown the polymerisation process to facilitate the release of water produced during the cross-linking of the prepolymers [11]. If curing is too rapid the trapped water may cause matrix cracking and delamination [11].

The above resin preparation, laminate fabrication, and curing procedures were repeated with the stacks of fibre sheets from the second and third sets, respectively.

2.6. Preparation of Test Specimens. After cooling to room temperature, each of the three cured composite plaques was cut into four smaller strips; each strip was approximately $2 \mathrm{~mm}$ thick and had dimensions of $280 \times 70 \mathrm{~mm}^{2}$ in order to correspond with the initial fibre sheet stacks of the same dimensions. The densities of the fibre and cured resin were obtained from their manufacturers as 1.5 and $1.8 \mathrm{~g} / \mathrm{cm}^{3}$, respectively. The composite strips were weighed to determine 
TABLE 1: Fibre mass and volume proportions in the composite strips.

\begin{tabular}{|c|c|c|c|c|c|c|c|c|}
\hline & $\begin{array}{c}\text { Mass of } \\
\text { fibres (g) }\end{array}$ & $\begin{array}{l}\text { Mass of } \\
\text { resin }(\mathrm{g})\end{array}$ & FMF (\%) & $\begin{array}{c}\text { Volume of } \\
\text { fibres } \\
\left(\mathrm{cm}^{3}\right)\end{array}$ & $\begin{array}{c}\text { Volume of } \\
\text { resin } \\
\left(\mathrm{cm}^{3}\right)\end{array}$ & $\begin{array}{c}\text { Volume of } \\
\text { voids } \\
\left(\mathrm{cm}^{3}\right)\end{array}$ & FVF (\%) & $\begin{array}{l}\text { Percentage } \\
\text { of porosity }\end{array}$ \\
\hline Set 1 & 20 & 19.35 & 51 & 13.33 & 10.75 & 15.12 & 34 & 38.6 \\
\hline Set 2 & 30 & 16.60 & 64 & 20.00 & 9.22 & 9.98 & 51 & 25.5 \\
\hline Set 3 & 40 & 13.41 & 75 & 26.67 & 7.45 & 5.08 & 68 & 13.0 \\
\hline
\end{tabular}

TABLE 2: Mean values of the mechanical properties of the composites.

\begin{tabular}{lccccc}
\hline $\begin{array}{l}\text { Fibre mass } \\
\text { fraction }(\%)\end{array}$ & $\begin{array}{c}\text { Tensile strength } \\
(\mathrm{MPa})\end{array}$ & $\begin{array}{c}\text { Tensile modulus } \\
(\mathrm{GPa})\end{array}$ & $\begin{array}{c}\text { Flexural } \\
\text { strength }(\mathrm{MPa})\end{array}$ & $\begin{array}{c}\text { Flexural } \\
\text { modulus }(\mathrm{GPa})\end{array}$ & $\begin{array}{c}\text { Interlaminar shear } \\
\text { strength }(\mathrm{MPa})\end{array}$ \\
\hline 51 & 77.2 & 4.32 & 95.4 & 6.96 & 11.2 \\
64 & 121 & 5.58 & 87.4 & 5.91 & 8.89 \\
75 & 86.6 & 4.78 & 48.8 & 3.12 & 5.77 \\
\hline
\end{tabular}

the fibre mass fraction (FMF) and to calculate the fibre volume fraction (FVF). Table 1 displays the outcomes.

2.7. Evaluation of Mechanical Properties. The composite strips were cut into the appropriate shapes for tensile, flexural, and interlaminar shear strength (ILSS) testing. For each test, a minimum of 5 specimens were tested for each category of FMF shown in Table 1. Specimen dimensions were measured to the nearest $0.05 \mathrm{~mm}$ with a sliding vernier. The specimens were conditioned at room temperature for at least 24 hours prior to testing, which was then carried out under the same conditions using a Universal Testing Machine (Shenzhen Reger Instrument Co. Ltd., Shenzhen, China). The tensile strength test was done in accordance with ASTM D3039 at a cross-head speed of $2 \mathrm{~mm} / \mathrm{min}$ on specimens with dimensions of $250 \times 15 \mathrm{~mm}^{2}$. The flexural strength test was done in accordance with ASTM D790 at a cross-head speed and was $2 \mathrm{~mm} / \mathrm{min}$ on specimens with dimensions of $100 \times$ $13 \mathrm{~mm}^{2}$. The short-beam shear method specified in ISO 14130 was used for the ILSS test. The specimens had dimensions of $20 \times 10 \mathrm{~mm}^{2}$ and the cross-head speed was $1 \mathrm{~mm} / \mathrm{min}$.

2.8. Tensile Fracture Surface Analysis with Scanning Electron Microscope (SEM). The tensile fracture surfaces of specimens that attained tensile strength values closest to the mean were gold-sputter coated for 20 minutes in a JEOL JFC-1600 Auto Fine Coater (JEOL Ltd., Japan). The fracture surfaces were then observed in a JEOL JSM-5610LV SEM (JEOL Ltd., Japan) with acceleration voltage of $5 \mathrm{kV}$.

2.9. Interlaminar Fracture Analysis with Digital Microscope. A Hirox KH-7700 digital microscope (Hirox Co. Ltd., Japan) was used to observe the damaged specimens of $51 \%$ FMF after the ILSS test. The cracked specimens with values of ILSS close to the mean were cut cross-wise $5 \mathrm{~mm}$ below the cracks and placed on the microscope slide to observe the cracks and to determine the shear mode(s).

2.10. Study of Viscoelasticity with Dynamic Mechanical Analysis (DMA). DMA was carried out to evaluate the storage and loss moduli and the damping properties $(\tan \delta)$ of the composites using a DMA Q800 instrument (TA Instruments Inc., United States). In addition to the specimens from the three categories of FMF in Table 1, a similarly cured control specimen with FMF of $0 \%$ was included in the analysis. All the specimens had dimensions of $50 \times 13 \mathrm{~mm}^{2}$ and they were clamped in the 3 -point bend mode. The strain amplitude and frequency were $15 \mu \mathrm{m}$ and $1.0 \mathrm{~Hz}$, respectively. The temperature was increased from 0 to $240^{\circ} \mathrm{C}$ at a heating rate of $5^{\circ} \mathrm{C} / \mathrm{min}$.

2.11. Evaluation of Thermostability with Thermogravimetric Analysis (TGA). The thermostability of the composites was assessed using a Perkin Pyris 1 TGA (PerkinElmer Inc., United States) instrument. Composite specimens from the three categories of FMF in Table 1 and a similarly cured control specimen with FMF of $0 \%$ were heated from 25 to $600^{\circ} \mathrm{C}$ at $20^{\circ} \mathrm{C} / \mathrm{min}$ under nitrogen flow rate of $20 \mathrm{~mL} / \mathrm{min}$.

\section{Results and Discussion}

Table 2 displays the results of the mechanical tests carried out on the composites. The strength and moduli values are shown plotted in Figures 1(a) and 1(b), respectively, with the error bars inserted at the respective standard deviations.

3.1. Tensile Properties. The mean tensile strength and modulus were significantly improved by the increase of FMF from 51 to $64 \%$. The tensile strength of $121 \mathrm{MPa}$ at $64 \%$ FMF is almost twice that of a unidirectionally stitched flax fabric-reinforced furan biocomposite, which attained tensile strength of $64 \mathrm{MPa}$ at $60 \% \mathrm{FMF}$ [14]. However, the tensile modulus of the flax-furan composite was much higher at $8.5 \mathrm{GPa}$, compared to just $5.6 \mathrm{GPa}$ in the current study. This can be attributed to the greater stiffness of the flax fibre, which has just one quarter $(3.3 \%)$ of the elongation at break of the CR fibre [15]. In PLA based composites, it has also been indicated that Cordenka fibre improves tensile strength, whilst flax fibre improves the tensile modulus [16]. Similar findings were obtained using Cordenka and 


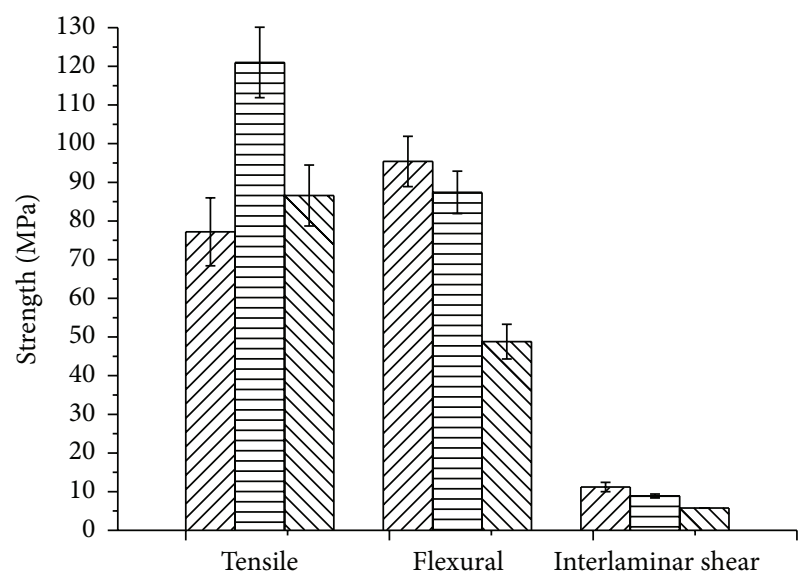

Fibre mass fraction एII 51\% 두 लाए $75 \%$

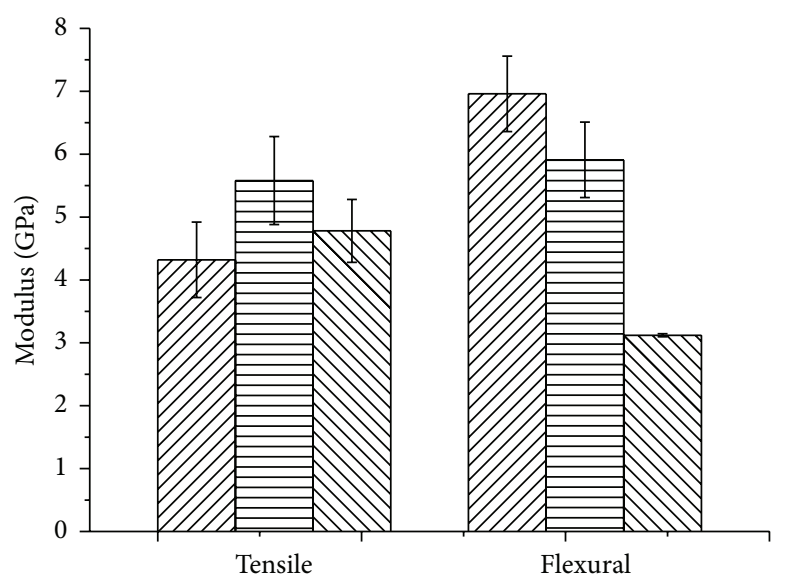

Fibre mass fraction

पIIS $51 \%$

Е $64 \%$

लाए $75 \%$

(a)

(b)

FIgure 1: (a) Tensile, flexural, and interlaminar shear strengths. (b) Tensile and flexural moduli.

flax fabrics in epoxy composites [17]. In the current study, further increase of the FMF from 64 to $75 \%$ resulted in a decrease of about $34 \mathrm{MPa}$ in the mean tensile strength. In another study, unidirectionally aligned kenaf fibre-reinforced furan biocomposite attained tensile strength and modulus of approximately $40 \mathrm{MPa}$ and $1.3 \mathrm{GPa}$, respectively [18]. In that study, the FMF was restricted to a considerably low $20 \%$, above which the tensile properties were observed to decrease sharply. The deterioration of the tensile properties above a certain FMF in that study correlates with the results of the current study. The decrease in tensile strength is caused by poor dispersion, which is a consequence of the high degree of proximity of the fibres to each other [19]. Poor dispersion leads to unreinforced matrix-only areas through which the stress of testing concentrates, leading to rapid crack propagation and ultimately rupture [20]. The tensile strength is also affected by the alignment of the fibres during fabrication [21]. In the current study, the fibres were manually aligned and stacked unidirectionally, a technique that becomes less reliable as the quantity of the fibres increases and may result in misalignment of some fibres. The misaligned fibres do not contribute enough support during testing [21].

3.2. Flexural Properties. The flexural properties deteriorated with the increase of FMF from 51 through $75 \%$. The greatest mean flexural strength and modulus were approximately $95 \mathrm{MPa}$ and $7.0 \mathrm{GPa}$, respectively, attained at 51\% FMF. The flexural strength in this case (where the FVF is 34\%) compares well with a value of $99 \mathrm{MPa}$ obtained with unidirectionally stitched flax fabric-reinforced furan resin at $41 \%$ FVF [7]. The flexural modulus in that study, however, was significantly higher at $9.6 \mathrm{GPa}$. For reference, a glass plain weave fabric-reinforced furan resin composite with $47 \%$ FVF attained flexural strength and modulus of $105 \mathrm{MPa}$ and
9.0 GPa, respectively [7]. In the current study, the flexural properties decrease at increasing fibre proportions because the flexure test has a compressive component in it, and the compressive strength of a composite is determined by the properties of the matrix and the fibre-matrix interface [17]. Furthermore, there was an increase in weak spaces in the composite due to reduced fibre wetting that occurs at higher FMF, which consequently reduced the flexural strength [22]. The weak areas consist of fibre sheet regions that have the least amount of resin wetting [11]. This effect is apparent in Table 1, where resin uptake is observed to decline as the fibre loading is increased. Thus, the furan matrix clearly dominates the flexural properties of this composite. However, it appears that the CR fibre of the current study could still compete well with the already established glass and flax fibres in furan composites, especially where the flexural strength is of prime interest. The optimum FMF that results in the best flexural strength and modulus has to be found through further research.

3.3. Interlaminar Properties. The ILSS decreased with the increase of FMF from 51 through $75 \%$. The greatest mean value was $11.2 \mathrm{MPa}$ at $51 \%$ FMF. For reference, a commercially available flax twill fabric-reinforced epoxy prepreg was found to have ILSS of $10.7 \mathrm{MPa}$ [17]. In the short-beam shear test, the ratio (support span length/specimen thickness) is much smaller $(10 / 2=5)$, compared to $80 / 2=40$ in the flexural strength test. The smaller ratio in the ILSS test causes the specimen to fail through shearing of its layers, as intended. These results indicate that the fibre-matrix interfacial adhesion deteriorated steadily with increased FMF.

3.4. Results of Analysis with SEM. Figure 2 shows SEM images of the tensile fracture surfaces. Figure 2(a) shows 


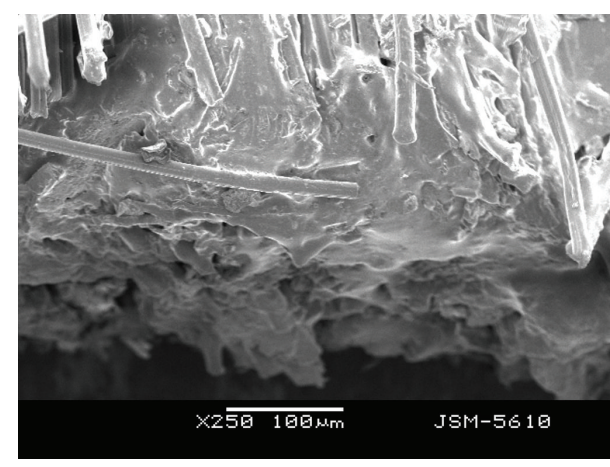

(a)

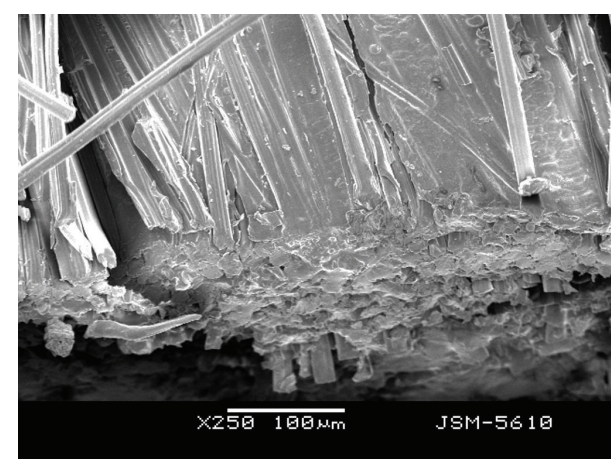

(b)

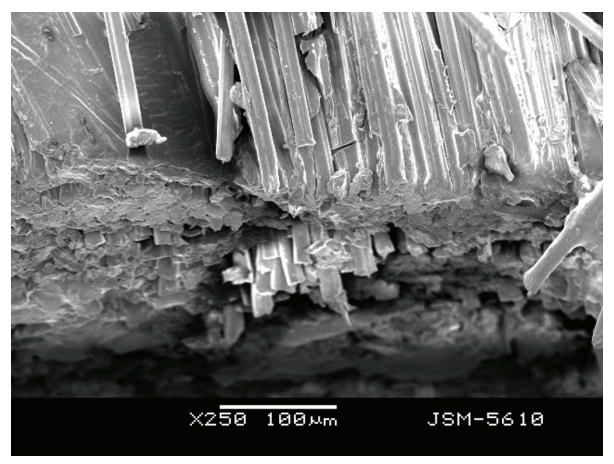

(c)

Figure 2: (a) SEM image of tensile fracture surface (51\% FMF). (b) SEM image of tensile fracture surface (64\% FMF). (c) SEM image of tensile fracture surface (75\% FMF).

a fracture surface from a specimen of 51\% FMF. The matrix appears prominently and exhibits signs of porosity, some of which can be attributed to water that got trapped during curing. Some fibres have been pulled out from the matrix and they appear to be smeared with matrix material, which is indicative of good fibre-matrix adhesion [8]. Figure 2(b) shows a fracture surface from a specimen that had $64 \%$ FMF. The matrix shows a high level of porosity and signs of brittle fracture, revealing some fibres still embedded within the matrix, whilst many were pulled out. Some fibres were also misaligned. The tensile properties were still improved, however, which means these adverse effects were outweighed by the reinforcing effect of the CR fibres. A high level of porosity was also observed in a unidirectional flax-furan resin biocomposite with $60 \% \mathrm{FMF}$, which was attributed to excessive resin bleed-out [14]. Figure 2(c) shows a fracture surface from a specimen that had 75\% FMF. The fibre-matrix interaction was not optimal, as there are many short pulledout fibres in proximity to each other. For comparison, a Cordenka fibre-reinforced PLA composite with 30\% FMF was found to have poor fibre-matrix adhesion due to long and clean pulled-out fibres [16]. In Figure 2(c) the fibres appear to have huddled together into bundles that led to dry spots and became interfacial weak areas; the huddling of the fibres can be attributed to hydrogen bonds that formed between them $[17,23]$. This is one major consequence of the high FMF. The large gaps between the fibres and the matrix are also the result of poor dispersion during fabrication [16].
3.5. Results of Analysis with Digital Microscope. Figure 3 shows cross section images of some specimens of $51 \%$ FMF from the short-beam shear test. In Figure 3(a), an intralaminar or matrix crack is seen extending from the edge of the specimen towards the interlaminar crack. The crack propagation was transferred from the matrix or the fibrematrix interface towards the fibre plies, causing delamination $[24,25]$. This type of crack behaviour signals satisfactory fibre-matrix compatibility [26]. Matrix cracks are one of the main causes of the commencement of delamination [27]. The cracks may initiate in the matrix due to its lower failure strain. The release of cure pressure can also result in fractures within the matrix [17]. Despite the extensive cracking, the specimens exhibited minimal deformation to their overall shapes, which is typical of a brittle material [28]. This can be seen in Figure 3(b), where the delamination crack runs in a fairly straight line across the specimen, and the outer edges of the specimen remained parallel to each other. The shear fracture modes are II and III.

3.6. Results of Viscoelastic Behaviour Study. Table 3 displays the data outputted by the DMA instrument. The viscoelastic behaviours of the composites and control specimen are shown in Figure 4.

In Figure 4(a), the storage moduli $\left(E^{\prime}\right)$ decreased with increasing temperature due to the deterioration of the elasticity of the furan matrix. The highest storage modulus at 


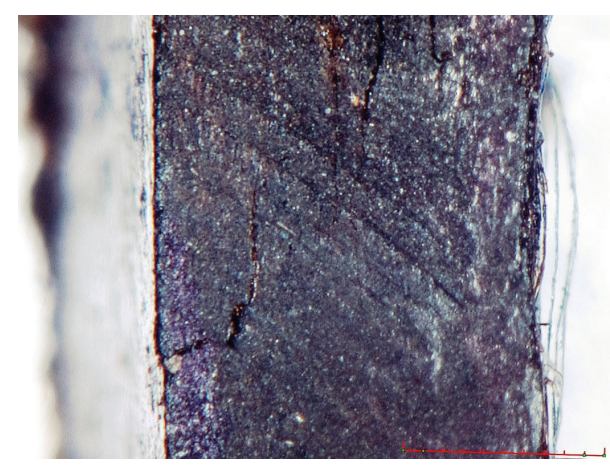

(a)

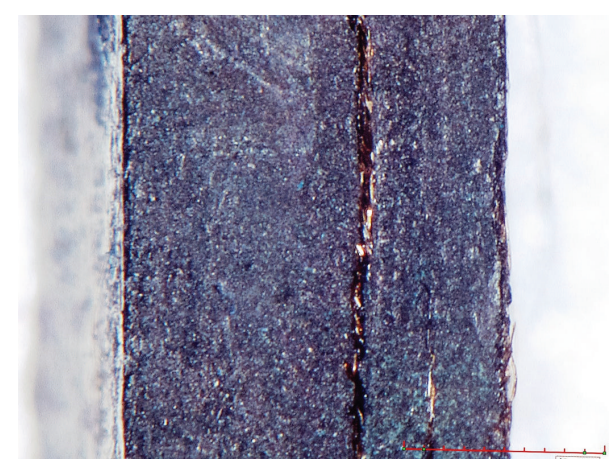

(b)

Figure 3: (a) Matrix cracking. (b) Delamination.

TABLE 3: Storage modulus, damping coefficient and glass transition temperature values of the composites and control specimen.

\begin{tabular}{lcccc}
\hline $\begin{array}{l}\text { Fibre mass } \\
\text { fraction }(\%)\end{array}$ & $\begin{array}{c}\text { Storage modulus at } \\
25^{\circ} \mathrm{C}(\mathrm{GPa})\end{array}$ & $\tan \delta$ at $25^{\circ} \mathrm{C}$ & $\begin{array}{c}\text { Glass transition } \\
\text { temperature }\left({ }^{\circ} \mathrm{C}\right)\end{array}$ & $\begin{array}{c}\tan \delta \text { at glass transition } \\
\text { temperature }\end{array}$ \\
\hline 0 & 0.5 & 0.028 & 90.3 & 0.092 \\
51 & 4.6 & 0.032 & 128 & 0.123 \\
64 & 4.1 & 0.033 & 122 & 0.109 \\
75 & 4.0 & 0.033 & 119 & 0.093 \\
\hline
\end{tabular}

room temperature $\left(25^{\circ} \mathrm{C}\right)$ was approximately $4.6 \mathrm{GPa}$, which was attained by the specimens with $51 \%$ FMF. For the three tested composites, the value of $E^{\prime}$ is observed to decrease with increasing FMF, a trend that is consistent with the flexural and interlaminar shear strengths. The three composites, however, had much higher values of $E^{\prime}$ than the control specimen of $0 \% \mathrm{FMF}$, which is an indication of the increased stiffness of the composites due to the reinforcing properties of the CR fibres. In addition, the curves of $E^{\prime}$ do not exhibit any increase in the value of $E^{\prime}$ in the tested temperature range, suggesting that the resin was cured sufficiently [29]. In Figure $4(\mathrm{~b})$, the loss moduli $\left(E^{\prime \prime}\right)$ are observed to reach maximum values corresponding with the respective glass transition temperatures $\left(T_{\mathrm{g}}\right)$. Incorporating the fibre reinforcement elevated the $T_{\mathrm{g}}$ of the resin. Amongst the three composites, however, the $T_{\mathrm{g}}$ decreased with increasing FMF. At higher FMF, it has been noted that the furan matrix becomes less reinforced as the fibres tend to huddle together. The data in Table 3 indicate that the three composites had similar damping coefficients $(\tan \delta)$ at $25^{\circ} \mathrm{C}$. Above $25^{\circ} \mathrm{C}$, the specimen with $51 \%$ FMF maintained the highest values of $\tan \delta$, which means it was the most efficient at absorbing and dissipating energy. This is due to the adequate wetting of the fibres by the resin, which enhanced the damping effect at the fibre-matrix interface during cyclic loading [30]. This is an important consideration for automotive applications, where the biocomposite is expected to absorb and dissipate vibrational energy safely and efficiently.

3.7. Results of Thermostability Study. Figure 5 shows the TGA curves of the specimens. The three composites and the control specimen each lost about $7 \%$ mass at $200^{\circ} \mathrm{C}$. Above $200^{\circ} \mathrm{C}$, the thermostability of the three composites appears to be improved over that of unreinforced furan resin. A mass loss of $10 \%$ corresponds with a temperature of approximately $260^{\circ} \mathrm{C}$ for the composites, whilst for unreinforced furan resin it is lower at approximately $220^{\circ} \mathrm{C}$. The three composites show rapid mass loss at approximately $275^{\circ} \mathrm{C}$, which can be attributed to the degradation of the cellulosic structures of the CR fibres [31]. This degradation became worse with the increase of FMF since although the fibres are completely enclosed within the furan matrix, at higher FMF there is less matrix material to protect the fibres from degrading [12]. Between 280 and $320^{\circ} \mathrm{C}$, the specimen with 51\% FMF lost $5 \%$ less mass compared to the other two specimens with the higher FMFs. The specimen with 51\% FMF also retained the greatest mass residue $(41.1 \%)$ at $600^{\circ} \mathrm{C}$, whilst the specimens with $64 \% \mathrm{FMF}$ and $75 \% \mathrm{FMF}$ retained mass residues of $34.0 \%$ and $13.5 \%$, respectively.

\section{Conclusions}

A full biocomposite has been successfully fabricated from high tenacity rayon fibre and furan resin. Study of the laminate cracking behaviour revealed the two materials to be compatible as a composite system. The comparisons made with related furan resin-based biocomposites indicated that the CR fibres are a viable reinforcement in such composites. In particular, the $\mathrm{CR}$ fibres will be a suitable candidate to replace flax fibres if the tensile strength is of prime interest. Furthermore, the tensile properties benefit from a fibre mass fraction that is just above $60 \%$; for additional improvements, it will be necessary to find means to stall the loss of fibre-matrix adhesion. One way to achieve this could 


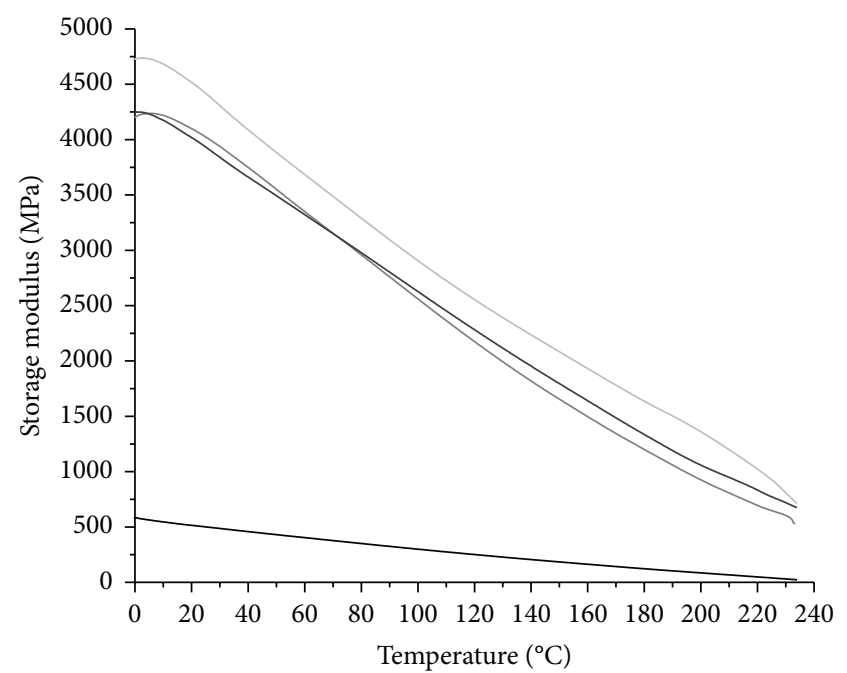

Fibre mass fraction

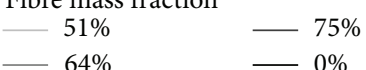

(a)
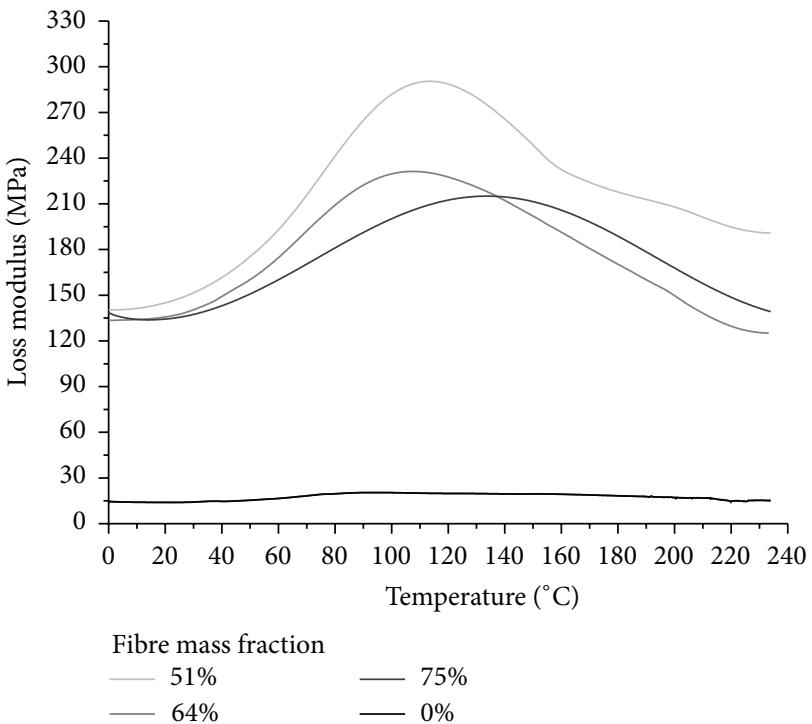

(b)

FIGURE 4: (a) Storage moduli of the composites and control specimen. (b) Loss moduli of the composites and control specimen.

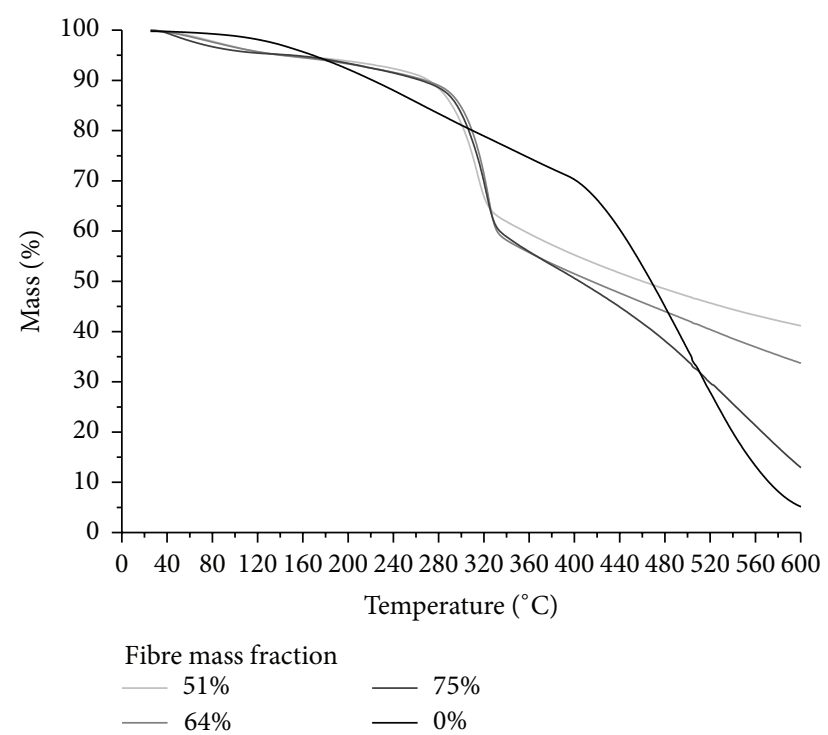

Figure 5: Thermogravimetric curves of the composites and control specimen.

be the incorporation of coupling agents to enhance the fibrematrix adhesion. Since the CR fibres provided similar flexural strength as glass fibres in furan resin biocomposites, the CR fibres may be a suitable substitute for glass fibres in these biocomposites. This would add the advantage of reduced weight, which is necessary in the automotive sector. More research is required to determine the optimum fibre mass fraction corresponding with the best flexural and dynamic mechanical properties. For better control of resin bleed-out to improve fibre wetting and reduce porosity, alternative fabrication techniques have to be investigated, for example, vacuum bagging. The fibres can also be stitched into a unidirectional fabric for better alignment.

\section{Conflict of Interests}

The authors declare that there is no conflict of interests regarding the publication of this paper.

\section{Acknowledgments}

The authors are very grateful to the management and staff at the Cordenka Shanghai Representative Office for their assistance in procuring the Cordenka CR fibre packages from Germany. Sales personnel at Hangzhou Tianyu Chemicals Company Ltd. are also acknowledged for providing the furan resin at a discounted price.

\section{References}

[1] O. Faruk, A. K. Bledzki, H.-P. Fink, and M. Sain, "Biocomposites reinforced with natural fibers: 2000-2010," Progress in Polymer Science, vol. 37, no. 11, pp. 1552-1596, 2012.

[2] M. J. John and S. Thomas, "Biofibres and biocomposites", Carbohydrate Polymers, vol. 71, no. 3, pp. 343-364, 2008.

[3] M. Choura, N. M. Belgacem, and A. Gandini, "Acid-catalyzed polycondensation of furfuryl alcohol: mechanisms of chromophore formation and cross-linking," Macromolecules, vol. 29, no. 11, pp. 3839-3850, 1996.

[4] A. Pessoa, I. M. Mancilha, and S. Sato, "Acid hydrolysis of hemicellulose from sugarcane bagasse," Brazilian Journal of Chemical Engineering, vol. 14, no. 3, 1997.

[5] X. Chen, H. Li, H. Luo, and M. Qiao, "Liquid phase hydrogenation of furfural to furfuryl alcohol over Mo-doped Co-B 
amorphous alloy catalysts," Applied Catalysis A, vol. 233, no. 12, pp. 13-20, 2002.

[6] Industrial Fiber Glass Specialities Inc, "Dual laminate construction for furan composite equipment-a bad idea," Tech. Rep., Industrial Fiber Glass Specialities Inc, Dayton, Ohio, USA, 1994.

[7] E. L. Arnold, B. M. Weager, H. E. Hoydonckx, and B. Madsen, "Next generation sustainable composites: development and processing of furan-flax biocomposites," in Proceedings of the 17th International Conference on Composite Materials (ICCM '09), Paper no. D9:13, Edinburgh, UK, 2009.

[8] J. Ganster and H.-P. Fink, "Novel cellulose fibre reinforced thermoplastic materials," Cellulose, vol. 13, no. 3, pp. 271-280, 2006.

[9] A. Mader, E. Volkmann, R. Einsiedel, and J. Müssig, "Impact and flexural properties of unidirectional man-made cellulose reinforced thermoset composites," Journal of Biobased Materials and Bioenergy, vol. 6, no. 4, pp. 481-492, 2012.

[10] Cordenka, "Composites," Tech. Rep., Cordenka, Obernburg, Germany, 2009, http://www.cordenka.com/composites.php.

[11] T. Tumolva, M. Kubouchi, and T. Sakai, "Development of abaca/furan green composites," in Proceedings of the 17th International Conference on Composite Materials (ICCM '09), paper D9:11, Edinburgh, UK, July 2009.

[12] T. Tumolva, M. Kubouchi, S. Aoki, and T. Sakai, "Evaluating the carbon storage potential of furan resin-based green composites," in Proceedings of the 18th International Conference on Composite Materials (ICCM '11), Paper no. W05-4, Jeju, Republic of Korea, 2011.

[13] A. Thygesen, B. Madsen, A. B. Thomsen, and H. Lilholt, "Effect of acidic conditions on interface and strength of cellulose fibres," in Proceedings of the 28th Risø International Symposium on Materials Science: Interface Design of Polymer Matrix Composites, Risø National Laboratory, Roskilde, Denmark, 2007.

[14] S. Giannis, E. Arnold, H. E. Hoydonckx, B. M. Weager, and R. H. Martin, "Development of high performance bio-composites based on furan bio-resins for vehicle panels," in Proceedings of the 13th European Conference on Composite Materials (ECCM '08), Paper no. 240, Stockholm, Sweden, 2008.

[15] D. B. Dittenber and H. V. S. Gangarao, "Critical review of recent publications on use of natural composites in infrastructure," Composites Part A: Applied Science and Manufacturing, vol. 43, no. 8, pp. 1419-1429, 2012.

[16] B. Bax and J. Müssig, "Impact and tensile properties of PLA/Cordenka and PLA/flax composites," Composites Science and Technology, vol. 68, no. 7-8, pp. 1601-1607, 2008.

[17] J. Meredith, S. R. Coles, R. Powe et al., "On the static and dynamic properties of flax and Cordenka epoxy composites," Composites Science and Technology, vol. 80, pp. 31-38, 2013.

[18] H. Deka, M. Misra, and A. Mohanty, "Renewable resource based 'all green composites' from kenaf biofiber and poly(furfuryl alcohol) bioresin," Industrial Crops and Products, vol. 41, no. 1, pp. 94-101, 2013.

[19] A. K. Bledzki and J. Gassan, "Composites reinforced with cellulose based fibres," Progress in Polymer Science, vol. 24, no. 2, pp. 221-274, 1999.

[20] D. P. Pfister and R. C. Larock, "Green composites from a conjugated linseed oil-based resin and wheat straw," Composites Part A: Applied Science and Manufacturing, vol. 41, no. 9, pp. 1279-1288, 2010.

[21] H. M. Akil, M. F. Omar, A. A. M. Mazuki, S. Safiee, Z. A. M. Ishak, and A. Abu Bakar, "Kenaf fiber reinforced composites: a review," Materials \& Design, vol. 32, no. 8-9, pp. 4107-4121, 2011.
[22] M. R. Rahman, M. M. Huque, M. N. Islam, and M. Hasan, "Mechanical properties of polypropylene composites reinforced with chemically treated abaca," Composites Part A: Applied Science and Manufacturing, vol. 40, no. 4, pp. 511-517, 2009.

[23] Y. Xie, C. A. S. Hill, Z. Xiao, H. Militz, and C. Mai, "Silane coupling agents used for natural fiber/polymer composites: a review," Composites A: Applied Science and Manufacturing, vol. 41, no. 7, pp. 806-819, 2010.

[24] K.-Y. Kim, L. Ye, and C. Yan, "Fracture behavior of polyetherimide (PEI) and interlaminar fracture of CF/PEI laminates at elevated temperatures," Polymer Composites, vol. 26, no. 1, pp. 20-28, 2005.

[25] A. B. De Morais, M. F. De Moura, A. T. Marques, and P. T. De Castro, "Mode-I interlaminar fracture of carbon/epoxy crossply composites," Composites Science and Technology, vol. 62, no. 5, pp. 679-686, 2002.

[26] N. Mahmoudi, "Effect of volume fiber and crack length on interlaminar fracture properties of glass fiber reinforced polyester composites (GF/PO composites)," Mechanika, vol. 20, no. 2, pp. 153-157, 2014.

[27] A. Ahmed and L. J. Sluys, "A numerical study on interacting damage mechanisms in FRP laminated composite plates," Heron, vol. 58, no. 1, pp. 61-85, 2013.

[28] M. S. Prasad, C. Venkatesha, and T. Jayaraju, "Experimental methods of determining fracture toughness of fiber reinforced polymer composites under various loading conditions," Journal of Minerals and Materials Characterization \& Engineering, vol. 10, no. 13, pp. 1263-1275, 2011.

[29] C. C. M. Ma, M. S. Yn, J. L. Han, C. J. Chang, and H. D. Wu, "Pultruded fibre-reinforced furfuryl alcohol resin composites: 2. Static, dynamic mechanical and thermal properties," Composites Manufacturing, vol. 6, no. 1, pp. 53-58, 1995.

[30] W. G. Trindade, W. Hoareau, J. D. Megiatto, I. A. T. Razera, A. Castellan, and E. Frollini, "Thermoset phenolic matrices reinforced with unmodified and surface-grafted furfuryl alcohol sugar cane bagasse and curaua fibers: properties of fibers and composites," Biomacromolecules, vol. 6, no. 5, pp. 2485-2496, 2005.

[31] M. Brebu and C. Vasile, "Thermal degradation of lignin-a review," Cellulose Chemistry and Technology, vol. 44, no. 9, pp. 353-363, 2010. 

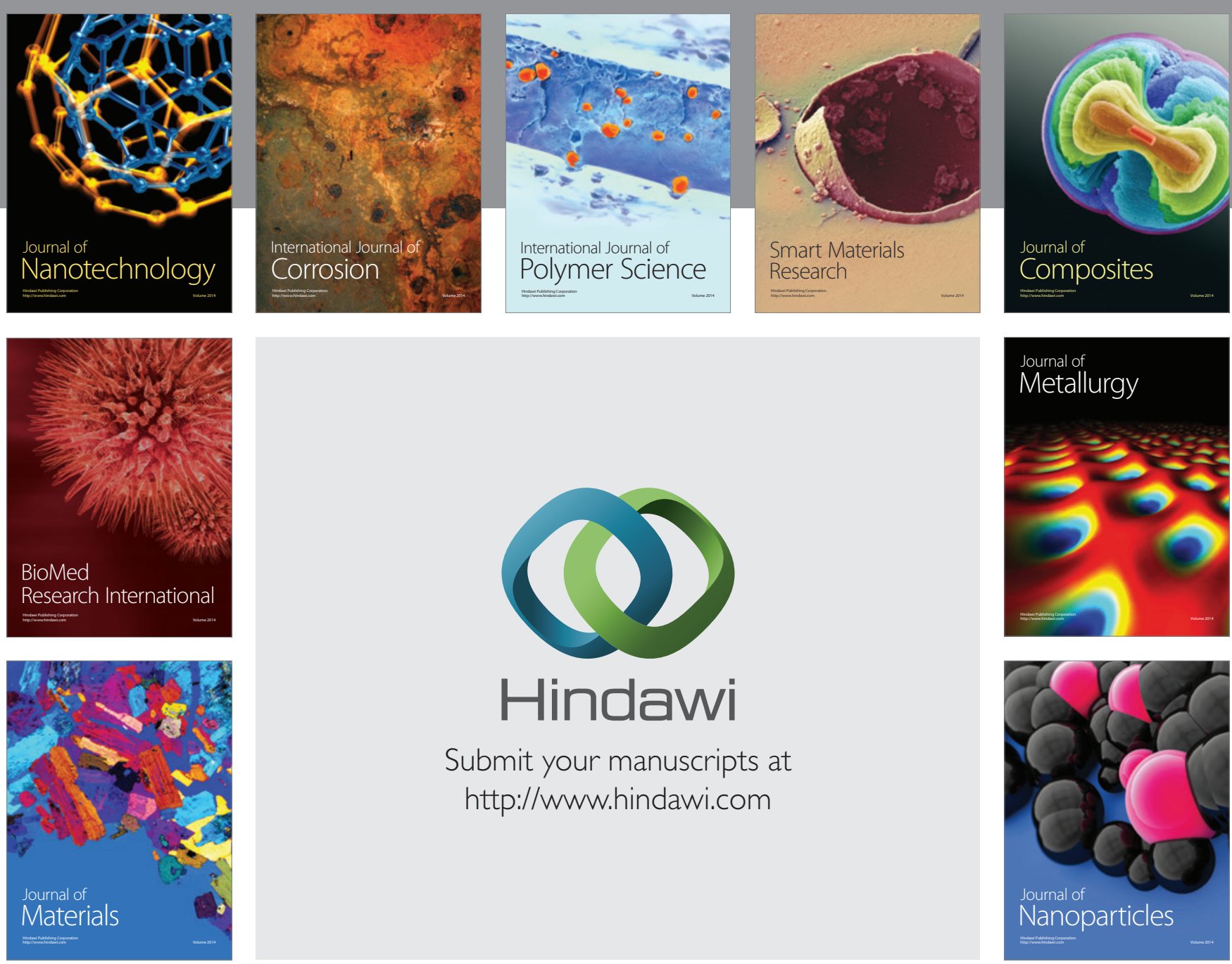

Submit your manuscripts at http://www.hindawi.com
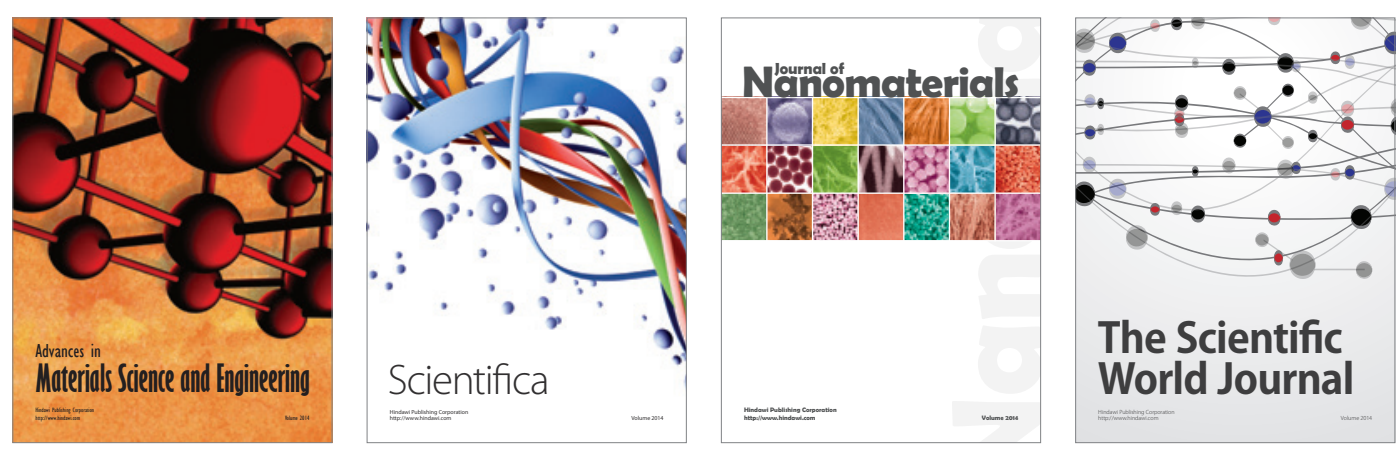

\section{The Scientific World Journal}
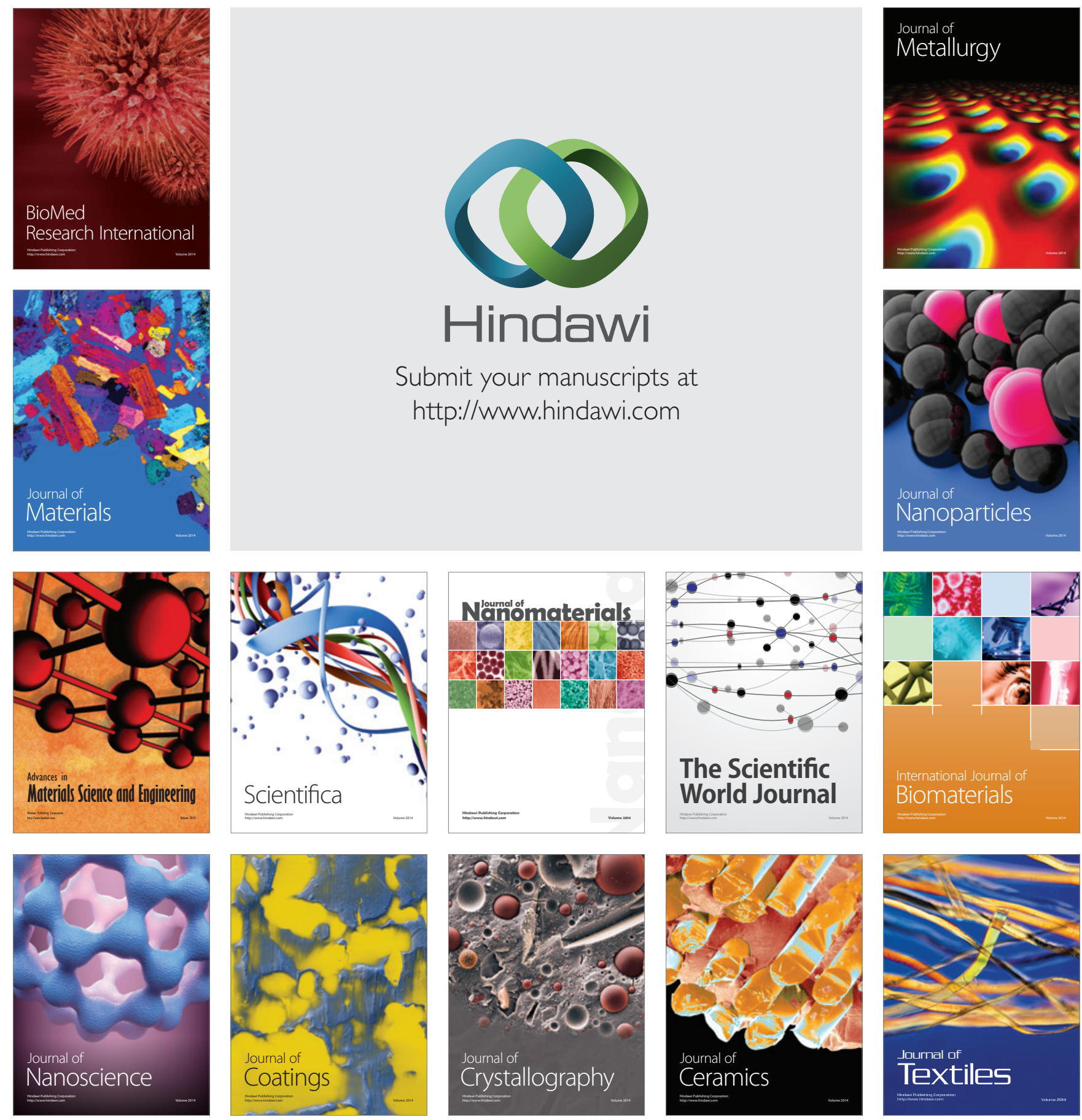